\title{
A Research on the Correlation between Linyi Dialect and XuanZiXi
}

\author{
Xiao-fei Han \\ School of Music, Linyi University, Shandong, China
}

\begin{abstract}
With a strong local color, the local dialect is the dominant language of the regional culture, and the main content of construction of the regional culture. This paper aims to analyze the similarities and differences between Linyi XuanZiXi and that of other places and the inheritance and development of XuanZiXi under the influence of Linyi dialect, in order to explore the correlation of the two and seek the ways to protect and develop XuanZiXi. The paper will carry on the analysis from the following aspects: identity and cultural identity of the dialect and local opera, cultural function of dialect and XuanZiXi, and the influence of dialect on the opera music creation.
\end{abstract}

Keywords — dialect, traditional opera, XuanZiXi, correlation

\section{临沂方言与弦子戏之关联探究}

\author{
韩小菲 \\ 临沂大学音乐学院，临沂，山东，中国
}

\begin{abstract}
摘 要 地方方言具有浓郁的地方特色, 是区域文化的主体性语言, 构建区域文化的主要内涵之一。而地方传统戏曲即是在这种 特别的语言文化基础上形成, 二者之间有着千丝万缕的关联。本文旨在通过分析临沂地方方言及地方传统戏曲弦子戏中音韵特征, 探 寻二者之间关联，探寻发展、保护地方传统戏曲弦子戏的途径。
\end{abstract}

关键词 方言, 传统戏曲, 弦子戏, 关联

俗话说: “十里不同风，百里不同俗”，相距几十里归 属同一区域文化范畴的两个自然村，或许在风俗、习惯等 方面也会存在一定差异。而语言表达作为人与人之间沟通 主要方式和工具, 从咬字、发音习惯等方面也是有差别的。 这些差别是否会对地方传统戏曲产生影响? 笔者认为这种 影响是现实存在的, 且方言从曲调、韵律、唱词、内涵等 方面均有影响, 也是音乐文化能否得到群体认同和文化认 同等方面的主要因素。

地方方言具有浓郁的地方特色, 是区域文化的主体性 语言, 构建区域文化的主要内涵之一。而地方传统戏曲即 是在这种特别的语言文化基础上形成, 在曲词构成、词曲 内容、文化内涵、情感风格的表现手法等方面, 均有地方 传统文化的烙印, 而方言亦是地方戏曲的标识, 也是地方 戏曲特色体现, 对其音乐创作方面有着深刻影响。

\section{1. 方言与地方戏曲的文化和身份认同}

临沂地近黄海, 南临苏北, 是鲁东南人口最多、面积 最大的地级城市, 总面积达 1.7 万平方公里, 是现代山东 与江苏毗邻的主要城市之一。临沂地形复杂, 最南端郯城 县、兰陵县、临沭县地属平原地带, 虽有马陵山脉绵延上 百公里, 但海拔不高且平缓, 北部沂南、费县、蒙阴则群 山环绕, 相对海拔较高且陡峭, 交通不便。另, 沂河、沭 河贯穿临沂南北, 自古便是主要的交通渠道。便利交通, 为民间传统音乐发展提供了物质基础和传承途径, 复杂地 形对其传统形式的留存提供了条件。

临沂市及所辖九县三区及新兴的经济开发区所操方言 均有差异, 但从整体看“临沂方言声调方面与普通话是相同 的, 也分为阴平、阳平、上声、去声四种声调。但是在调 值方面也存在差别, 临沂方言中去调和阴平调都是曲降调 [1], 以临沂市兰山区为中心向周边县区辐射, 可以分以下 几个不同类别的方言区域: “临沂北的莒南、沂南、沂水等 
地读零声母, 韵母相应为齐齿呼或撮口呼; 平邑、蒙阴、 费县不分尖团, 其余各县分尖团; 沂南沂水等地读舌根鼻 音声母 $\eta[2]$ ”等等。再如: “喝水的人”一词, 临沂市以南县 区大多说“喝（hě）匪(féi)地人（rēn）”, 而沂南说的是“哈 匪(féi)地银”; 临沂南郯城在形容空气很脏很呛会用“阿 (ă) 得慌” 来表示, 沂南方言是 “怪棒银啊” 等等。仅百公里之遥 的临沂南北两地县区, 咬字发音差别便如此之大, 而分布 于全国各地依附于地方方言的戏曲音乐也会因方言的不同 而各有特色。正如季国平所说: “作为民族戏曲艺术, 方言、 声腔与剧种是一体的, 无论是剧本创作、音乐创作还是演 员演唱、都不可违背。字、腔相倚, 关系特殊而密切。”[3] 元代燕南芝庵著的《唱论》中论述了唱曲要领, 乐曲 的地方特色, 并提到了咬字、发音是唱腔的关键。朱权《太 和正音谱》卷上 《词林须知》录本多出的“北音为曲, 南音 为歌”两句, 解释了《唱论》中的“南人不曲, 北人不歌”词 条; 如此都说明了区域文化不同导致的戏曲文化差异, 也 产生了区域差别的认同文化。

这里所提到的文化认同, 是指在地方方言影响下而产 生的具有地方特色的戏曲文化, 并得到本地群众认可、喜 爱, 并传承、发展。弦子戏作为古代 (民间流传弦子戏始 于汉代, 兴于唐代, 民间传承的弦子戏出自唐代宫廷）传 承发展至今的一个古老戏曲形式, 在全国各地很多地方均 有遗存, 如山东菏泽大弦子戏、临沂沂南的弦子戏等地, 从历史发展脉络来看, 属同宗同源之戏曲种类。在沂南弦 子戏的发展历程中, 受当地文化、风俗、方言等方面的影 响, 其曲牌、伴奏乐器、咬字等方面多多少少已发生变化, 因弦子这种由戏班自制的独特乐器, 沂南“弦子戏”而得名。 弦子戏有几百支传统曲牌, 其核心唱腔是“五大曲”, 即《黄 莺》、《锁南枝》、《娃娃调》、《山坡羊》、《青阳子》, 根据史 料记载唐大曲曲名, 其中《黄莺》与唐大曲《黄莺儿》同 名。据明沈德符《万历野获编》卷二十五记载: “元人小令, 行于燕赵, 后浸淫日盛, 自宣正至成弘后, 中原又行《锁 南枝》、《傍妆台》、《山坡羊》之属。…… 《山坡羊》者 李、何二公所喜, 今南北词俱有此名, 但北方惟盛《数落 山坡羊》, 其曲自宣、大、辽陈三镇传来, 今京师技女, 惯 以此充弦索北调。其语秽柿鄙浅, 并桑誉之音, 亦离去已 远, 而羁人游婿, 嗜之独深, 丙夜开樽, 争先招致。”这段 资料中其中《山坡羊》、《锁南枝》与沂南弦子戏核心唱腔“五 大曲”中的《山坡羊》、《锁南枝》名称一样, 可见其与唐代 大曲有一定渊源。另资料中提到的 “桑誉之音”即是郑卫之 音, 大致是说中州 (古时对现在河南省的一个称谓) 方言 的音乐形式。也即是说, 资料中提到的相关曲牌在当时即 以用方言演唱, 体现了中州地方特色。而沂南弦子戏的《娃 娃调》、《锁南枝》等也与我国很多地方戏以及曲艺音乐中
的曲牌相同, 但因其所处地域文化及方言影响, 在内容长 短、曲调音韵等方面却也存在着很大差异。正所谓乡音连 着乡情, 有着浓郁乡音的弦子戏, 因其词韵与方言的完美 结合, 特别是说白用地道的沂南方言表达, 而受到当地百 姓认可和追捧。据当地文化馆统计所得, 在新中国成立后, 沂南县张庄全村 $80 \%$ 的村民都会唱弦子戏的几个剧目。据 当地民间艺人沂南弦子戏第九代传人尹成恩老人介绍: “我 小时候村里有四五十口人就是以唱戏为主, 其他什么都不 做, 逢年过节、婚丧嫁娶在村里搭台子唱戏, 有时还走村 串户的表演相当热闹。”而当尹成恩老人的老伴（妻子）过 世后, 他不但没有在家里哭丧, 反而在外唱戏, 他回答村 里人的质问是: “哭和唱一个味, 因为我把情感全部表达在 戏中, 入戏了就忘记一切。”

\section{2. 方言文化对戏曲音乐创作的影响及文化功能体现}

\section{1 方言文化对戏曲音乐创作的影响}

所谓方言文化, 笔者认为是在地方特有语音为主体的 发音基础上随之产生的文化性能和文化内涵。对依附于此 的地方音乐特别是戏曲音乐创作从剧本内容、旋律构成、 说白、人物形象塑造等方面均有深刻影响。

正因为字的发音与戏曲演唱之间的必然联系和完美结 合, 所以地方戏曲均带有浓郁的方言特色。如沂南弦子戏 中的沂南方言腔调等, 特别是对白部分, 更把地方方言发 挥的淋漓尽致, 彰显了沂南弦子戏浓郁地方特色的独特魅 力。正如李首明在《论方言与地方戏音乐的互动关系》中 所论: “作为戏曲唱腔所用的语言虽然在形成之初以各地的 方言为基础, .....虽然戏曲唱腔与方言有一定区别, 但地 方戏曲的唱腔始终以当地方言的语音语调作为音乐设计的 主要因素这一点却没有变化。而且器乐音乐作为戏曲音乐 的主要组成部分, 与唱腔音乐在旋律风格、调式调性等方 面不可分而视之, ...... [4]"。沂南弦子戏的演员以当地土生 土长的庄户百姓为主体, 根据传承下来的曲牌, 以历史故 事及身边发生的故事为内容, 进行编创, 用他们特有的乐 器弦子为主进行伴奏 (沂南弦子戏的主要伴奏乐器是弦子、 曲笛、笙三种乐器, 另有二胡、扬琴、低胡及㭻呐以及打 击乐器等)。此些均离不开其依存环境, 由方言文化所赋予 的影响也就不言而喻了。

沂南弦子戏受当地方言文化影响的同时, 也把留存于 弦子戏中的特殊文化通过表演传播给当地百姓群体, 笔者 认为这即是弦子戏的文化传播功能。方言文化与弦子戏二 者相辅相成, 互为载体, 及弘扬了地方特色文化, 同时也 彰显了方言文化的强烈影响力。 


\section{2 文化功能体现}

从文化人类学符号学的观点看, 地方方言即是代表某 地文化特征的符号, 地方戏曲也是代表某地地方传统音乐 文化的符号。

符号不但是标识, 也代表了地域认同、文化认同和身 份认同。如贺知章的 《回乡偶书》: “少小离家老大回, 乡 音无改䯶毛衰。儿童相见不相识, 笑问客从何处来。”虽表 达的是久客异乡、缅怀故里的感怀诗, 但也体现了对故土 的感念, 乡音未改也是其表达思念的一种方式, 或说是其 表达故土难忘的符号和标识。类似的表达方式有很多, 自 古便有在各大经济繁茂的城市设立某地标识的商会, 也有 专门表演地方传统戏曲的班社组织, 甚至在一些茶楼酒肆 表演, 如山西梆子在北京、天津表演时, 身处北京、天津 的山陕人均去观看演出等等, 这大都是身在异乡人们寻求 故土的一种情感寄托，也是他们对乡音的文化认同。

而作为戏曲音乐一弦子戏的表演者, 本身即是操有浓 郁地方方言的人群, 他们即说方言有把文艺化、戏曲化的 方言音韵和习惯自然运用到弦子戏中, 强化弦子戏的地方 气息的同时，也成为表演者自我身份体现的符号。

\section{3. 小义弦子戏传承发展保护措施}

沂南弦子戏发展到今已有几百年的历史, 明末清初弦 子戏在鲁南地区十分盛行, 到清代乾隆年间, 因当时在沂 水县衙供职的尹廷佩酷爱弦子戏, 后创办了弦子戏班社而 发展起来。戏班子的建立, 对弦子戏的发展、传播有着很 大的带动作用, 因而沂南周边县区均纷纷建立起弦子戏班 子, 如临沂的徐庄村、前洞门村等发展至今。

新中国成立以后沂南弦子戏在当地的影响颇大, 戏班 子人数最多时达到近 50 人, 家家户户都能唱上几段, 而村 里百姓上了舞台, 生、旦、净、丑均能装扮, 并各司其职, 演绎长达数小时的弦子戏经典剧目, 如《西湖景》、《珍珠 衫》等, 可见其喜爱程度。随着文革的影响, 很多经典剧 目在当时禁演, 但也被一些酷爱弦子戏的老艺人保留下来, 据统计, 弦子戏原有传统剧目 70 多, 现在仅流唱的有 30 多个, 而曲牌有 100 多个。

上世纪 80 年代以后, 随着经济的飞速发展, 面对充斥 着多种多样诱惑的复杂社会环境, 越来越多的年轻人对传 统戏曲失去兴趣, 这是弦子戏能否传承发展的主要矛盾之 一, 也是致使弦子戏面临着无人问津局面主要原因之一。 而弦子戏艺人年龄普遍偏高, 传承后继无人。由于旧时条 件所限, 很多经典剧目遗失。弦子戏如何传承、发展已成 为目前急需解决的首要问题。笔者根据前辈学者经验并走 访调研, 给出以下几点浅薄看法, 试图为沂南弦子戏的传 承保护探寻发展途径:
3.1 只有改变才能进步, 才能发展

而改变不是盲从, 不是推翻, 是在保留传统的同时创 新作品内容及形式, 是一个渐变的过程, 是为扩大观众群 体类别, 适合多种、多层次观众群体。如梅兰芳先生说: “我 改戏不喜欢把一个流传很久而观众已经熟悉了的老戏, 一 下子就大刀阔斧地改得面目全非, 叫观众看了不像那出戏。 这样做, 观众是不容易接受的。我采用逐步修改的方法。 等到积累了许多次的修改, 实际上已经跟当年的老样子大 不相同了, 可是观众在我逐步修改的过程中, 逐渐地也就 看惯了 [5]。也即是说, 即便改戏、更新老戏, 也不要太突 兀, 要循序渐进。

针对喜爱传统曲目的观众群体, 保留经典传统曲目, 保证高质量演出效果; 对年轻一代观众群体, 在传统剧目 基础上, 创编符合此类群体剧目等, 以期达到类型多样, 品类齐全。另外, 新创编曲目一定要以尊重传统和观众为 前提, 可“生戏熟曲”, 以期与多层次观众群体产生共鸣, 并得到认可、认同。

3.2 传承思想要改变, 避免“猫教老虎本领留一手、教会徒 弟饿死师傅”的心态

对旧时遗留的传承观念应逐渐转变, 以更好传承发展 弦子戏为前提, 培养年青一代学习兴趣, 并能倾囊相授专 业技能，才能更好发展。

\section{3 创新发展要与新时期发展现状相结合}

通过地方政府及文化机构, 开展文化演出宣传, 与当 地百姓亲密接触, 产生共鸣, 以期更好发展。

3.4 建立弦子戏发展商业链, 打破其有演员有剧目无经费的 虍尤局面

可以通过商业化链接, 开拓市场, 把弦子戏从原来的 仅以娱乐、消遣的“玩意”, 向即娱乐又收益的方向发展。 如兰陵县柳琴剧团, 为更好传承发展柳琴戏, 把部分经典 作品, 通过现代录像机等先进设备拍摄成集, 制作光盘。 既可以更好留存传统剧目, 还可带来部分经济收益, 也可 进行更好文化艺术宣传。弦子戏能否依据现状, 参照此类 做法, 而不盲从, 适当制作、宣传?

\section{5 地方传统音乐进课堂。}

近几年响应国家号召, 很多地方院校引入地方传统音 乐进课堂, 临沂大学更是把地方传统民歌、柳琴戏等带入 课堂教学中, 学生在感受地方传统音乐文化魅力的同时也 接受和学习了地方传统音乐文化, 为其发展开辟新径。弦 
子戏的发展也可尝试此种方法, 进入中小学、大学课堂, 让民族传统艺术在新一代的学生中产生共鸣, 为更好传承 民族传统艺术奠定坚实基础。

\section{参考文献(Reference)}

[1] Li Shouming. The Interaction between Dialect and Local Opera Music. China Musicology(Quarterly), 2007(4).

[2] The Theory of Singing by Yan Nanzhi'an. Chinese Classical Opera Works Integration (1), Chinese Drama Press, 1959.

[3] Ji Guoping. Dialect, Tune and New Drama Creation. Chinese Drama, 2007.10.18.

[4] Zhao Shufeng. The Businessmen from Shanxi and Shaanxi and
Bangzi Opera. Beijing Culture and Art Publishing House, 1996.

[5] Liu Xiaojuan. A Study of Zero Onset in Linyi Dialect. Shandong Normal University, 2011, 5.

[6] Sun Congyin. The Relationship between Opera Singing and Language. The People's Music Publishing House, 1983.

[7] Peng Cheng. "JunGong tone" Modal System and its Applications and Evolution in China in the 20th Century Composers. St. Petersburg Composer Press, 2013, 7.

[8] Peng Cheng. The Moscow School of Harmony and Its Inheritance Relationship. China Musicology(Quarterly), 2007(2), 119-124. 